\title{
Obesity and asthma: an association modified by age
}

\author{
F.J.Gonzalez-Barcala ${ }^{a}$, S.Pertega ${ }^{b}$, T.Perez-Castro ${ }^{c}$, M.Sampedro ${ }^{\text {, }}$, J.Sanchez- \\ Lastres $^{\mathrm{d}}$, M.A.San-Jose-Gonzalez ${ }^{\mathrm{d}}$, L.Bamonde ${ }^{\mathrm{d}}$, L.Garnelo ${ }^{\mathrm{d}}$, L.Valdés- \\ Cuadrado $^{\text {a }}$ J.D.Moure ${ }^{\mathrm{d}}$, J.M.Carreira ${ }^{\mathrm{e}}$, A.Lopez-Silvarrey ${ }^{\mathrm{f}}$
}

\author{
${ }^{a}$ Department of Respiratory Disease, Clinic Universitary Hospital, Santiago de Compostela, Spain \\ ${ }^{b}$ Clinical Epidemiology and Biostatistics Unit, University Hospital Complex, A Coruña, Spain \\ ${ }^{c}$ University College of Health Sciences, Universidade de A Coruña, A Coruña, Spain \\ ${ }^{d}$ Department of Paediatrics, Servicio Galego de Saude, Galicia, Spain \\ ${ }^{e}$ Radiology Department, University of Santiago de Compostela, Santiago de Compostela, Spain
}

${ }^{f}$ Maria Jose Jove Foundation, A Coruña, Spain

\begin{abstract}
Background. Some studies indicate some causal relationship between obesity and asthma, while others show inconsistent results. Our objective was to evaluate the prevalence of asthma according to obesity in children. Methods. A cross-sectional study, following the ISAAC study methodology, was conducted on two randomly selected groups consisting of 6-7 year-old children $(n=7485)$ and 13-14 year-old adolescents $(n=8496)$. The asthma symptoms and potential risk factors were determined from the questionnaire. Overweight and obesity were defined based on the body mass index.

Multiple logistic regression was used to obtain adjusted prevalence odds ratios (OR) and 95\% confidence intervals.

Results. Obesity was associated with an increase in wheezing ever (OR: 1.35) and exercise-induced asthma (OR: 1.62) in the 6-7 year-old group. No significant relationship was observed in the adolescent population. Conclusion. Obesity was associated with a higher prevalence of asthma in young children, but not in adolescents.
\end{abstract}

Keywords

Paediatric asthma; Obesity; Risk factor; Age 


\section{Introduction}

Both the prevalence of asthma and that of obesity appear to have increased in the childhood population in the last few years, particularly in developed countries. ${ }^{1,2}$ The studies published on the childhood population are inconsistent, as some show an increase in asthma prevalence in those who are obese, ${ }^{3,4}$ while others did not observe any relationship between obesity and asthma prevalence. ${ }^{5,6}$

Moreover, the importance of environmental and socio- economic factors in asthma prevalence is known, as such that the influence of a risk factor may be different between one population and another. $^{7,8}$

The purpose of our study was to evaluate the prevalence of asthma according to obesity in a large sample of the child and adolescent population in our region.

\section{Material and methods}

A study was conducted using the methodology of the Inter- national Study of Asthma and Allergies in Childhood (ISAAC) (http://isaac.auckland.ac.nz). A written questionnaire previously translated and validated in Spanish was used for the purpose of this study. ${ }^{9,10}$

The population studied were two groups of children, one with 6-7 year-olds (young children), and another with 13-14 year-olds (adolescents), from six of the main Health Areas in Galicia (Spain), which include a population of 1.9 million $(69 \%)$ of the total population of the Autonomous Community. The schools required to include 1000 validated questionnaires from each Health Area were randomly selected, and included all children of the targeted age range in each school. Schools that refused to participate were replaced by others.

The field work was done between October 2006 and February 2007. The A Coruña Health Area was excluded, as the study was conducted there in 2003 and its results are included in other publications. 9,10

Permission was requested from the parents or guardians, who also answered the questionnaire for the 6-7 year- old group, while in the older age group the questionnaire response were made by the children themselves.

The questionnaire data were entered manually into a data base in accordance with the ISAAC protocols, using double entry with subsequent validation.

The environmental questionnaire included questions about asthma symptoms, self-reported height and weight, presence of a dog or cat in the home, parental smoking habits, parental asthma history, and maternal education level ( Tables 1 and 2 ). 
Table 1. Prevalence of asthma symptoms

\begin{tabular}{|c|c|c|c|c|}
\hline & \multicolumn{2}{|c|}{$6-7$ years } & \multicolumn{2}{|c|}{ 13-14 years } \\
\hline & $\mathrm{N}$ & $\%$ & $\mathrm{~N}$ & $\%$ \\
\hline \multicolumn{5}{|c|}{ Wheezing ever } \\
\hline No & 4809 & 61.33 & 6915 & 76.7 \\
\hline Yes & 3038 & 38.7 & 2099 & 23.3 \\
\hline \multicolumn{5}{|c|}{ Current asthma } \\
\hline No & 6815 & 86.8 & 7822 & 86.8 \\
\hline Yes & 1032 & 13.2 & 1192 & 13.2 \\
\hline \multicolumn{5}{|c|}{ Exercise-induced asthma } \\
\hline No & 7368 & 93.9 & 7204 & 79.9 \\
\hline Yes & 479 & 6.1 & 1810 & 20.1 \\
\hline \multicolumn{5}{|c|}{ Severe asthma } \\
\hline No & 7485 & 95.4 & 8496 & 94.3 \\
\hline Yes & 362 & 4.6 & 518 & 5.7 \\
\hline
\end{tabular}

All values as number of cases ( $\mathrm{N}$ ) and percentage (\%).

Table 2. Main characteristics of the children and prevalence of risk factors.

\begin{tabular}{|c|c|c|c|c|}
\hline & \multicolumn{2}{|c|}{$6-7$ years } & \multicolumn{2}{|c|}{ 13-14 years } \\
\hline & $\mathrm{N}$ & $\%$ & $\mathrm{~N}$ & $\%$ \\
\hline \multicolumn{5}{|l|}{ Gender } \\
\hline Male & 3983 & 50.8 & 4599 & 51.0 \\
\hline Female & 3864 & 49.2 & 4415 & 49.0 \\
\hline \multicolumn{5}{|l|}{ Obesity } \\
\hline Normal weight & 5261 & 67 & 7421 & 82.3 \\
\hline Overweight & 1834 & 23.4 & 1396 & 15.5 \\
\hline Obesity & 752 & 9.6 & 197 & 2.2 \\
\hline \multicolumn{5}{|c|}{ Cat keeping in the past 12 months } \\
\hline No & 7152 & 92.9 & 7501 & 84.0 \\
\hline Yes & 545 & 7.1 & 1431 & 16.0 \\
\hline \multicolumn{5}{|c|}{ Cat keeping in the first year of life } \\
\hline No & 7371 & 94.6 & 5641 & 88.8 \\
\hline Ye s & 423 & 5.4 & 710 & 11.2 \\
\hline \multicolumn{5}{|c|}{ Dog keeping in the past 12 months } \\
\hline No & 6749 & 88.1 & 6367 & 71.3 \\
\hline Ye s & 910 & 11.9 & 2558 & 28.7 \\
\hline \multicolumn{5}{|c|}{ Dog keeping in the first year of life } \\
\hline No & 6999 & 90.1 & 5073 & 79.8 \\
\hline Yes & 772 & 9.9 & 1287 & 20.2 \\
\hline \multicolumn{5}{|l|}{ Maternal education } \\
\hline No education/elementary & 2099 & 27.2 & 1848 & 21.3 \\
\hline High school & 2955 & 38.2 & 3766 & 43.4 \\
\hline University & 2672 & 34.6 & 3069 & 35.3 \\
\hline \multicolumn{5}{|l|}{ Parental asthma } \\
\hline Neither parent asthma & 4304 & 87.9 & 4269 & 90.1 \\
\hline Some parent asthma & 590 & 12.1 & 468 & 9.9 \\
\hline \multicolumn{5}{|l|}{ Parental smoking } \\
\hline Neither parent smoke & 3795 & 49.8 & 4271 & 48.5 \\
\hline Father only & 1427 & 18.7 & 1254 & 14.3 \\
\hline Mother only & 994 & 13.0 & 1578 & 17.9 \\
\hline Both parents & 1404 & 18.4 & 1696 & 19.3 \\
\hline
\end{tabular}

All values as number of cases ( $\mathrm{N}$ ) and percentage (\%). 
For the purpose of this study, Wheezing ever was defined as a positive answer to the question "Has your child ever had wheezing or whistling in the chest at any time in the past?"

Current asthma was defined as a positive answer to the question "Has your child had wheezing or whistling in the chest during the last 12 months?",

Severe asthma was defining as a combination of the three questions assessing the severity of asthma: "How many attacks of wheeze has your child had during the last 12 months? (none, 1-3, $4-12,>12)$ ", " 'In the last 12 months, how often on average has your child's sleep been disturbed due to wheezing? (never, $<1$ night/week, $\geq 1$ nights/week)", and "In the last 12 months, has wheezing been severe enough to limit your child's speech to only one or two words at a time between breaths?"'. Children were considered to have current severe asthma when there were $\geq 4$ asthma attacks or when sleep was disturbed $\geq 1$ nights/week or when there had been an episode of speech limitation.

Exercise-induced asthma was defined as a positive answer to the question, "In the last 12 months, has your child's chest sounded wheezy during or after exercise?', 9,11,12

Obesity and overweight were defined in accordance with the Body Mass Index (BMI) cut-off points set by Cole et al., for each group by age and sex. ${ }^{13}$ Based on this, three groups were established; normal weight, overweight, and obese.

\section{Data analysis}

Multiple logistic regression was used to obtain adjusted prevalence odds ratios (OR) and 95\% confidence intervals (95\% CI) between asthma symptoms of schoolchildren and obesity. Children with normal weight were taken as a reference for calculating the ORs of the asthma symptoms for the overweight and obese categories.

These calculations were preferred to other methods (for example, linear regression) which do not provide information on risk increase, and which require statistical assumptions (such as linearity) that are unverifiable in empirical conditions.

In the multivariate analysis, the results are presented adjusted for gender, dog or cat in the home, parental smoking, parental asthma, and maternal education.

The children with incomplete data were excluded from this study.

The statistical analysis was performed using the software SPSS 17.0

The study was approved by the Clinical Research Ethics Committee of Galicia.

\section{Results}

The response rate in the 6-7 year-old group was $72.4 \%$, including 7847 valid cases. The response rate was higher $(84.4 \%, 9014$ cases $)$ in the adolescent group.

The prevalence of asthma in the lower age group was $39.0 \%$, that of current asthma $13.5 \%$, severe asthma $4.9 \%$, and exercise-induced asthma 6.4\%. In the 13-14 year-olds these prevalences were $23.0 \%, 13.2 \%, 5.8 \%$ and $20.0 \%$, respectively (Table 1 ).

The prevalence of overweight was $9.6 \%$ in the younger children, and $2.2 \%$ in the adolescents, while $23.4 \%$ of the 6-7 year-old group and $15.5 \%$ of the $13-14$ year-olds were obese (Table 2). 
Obesity was associated with an increase in the probability of wheezing ever (OR: 1.35, 95\% CI: 1.10-1.66) and exercise- induced asthma (OR: 1.62, 95\% CI: 1.10-2.36) in the 6-7 year age group. No significant influence of obesity was observed in the rest of the variables analysed in this group (Table 3).

Table 3. Odds ratio for prevalence of asthma symptoms according to obesity and overweight in children and adolescents.

\begin{tabular}{lllll}
\hline & $\begin{array}{l}\text { Wheezing ever } \\
\text { OR }(95 \% \text { CI })\end{array}$ & $\begin{array}{l}\text { Current asthma } \\
\text { OR }(95 \% \mathrm{CI})\end{array}$ & $\begin{array}{l}\text { Exercise-induced asthma } \\
\text { OR }(95 \% \mathrm{CI})\end{array}$ & $\begin{array}{l}\text { Severe asthma OR } \\
(95 \% \mathrm{CI})\end{array}$ \\
\hline $\begin{array}{l}\text { 6-7 years old } \\
\text { Normal weight }\end{array}$ & 1 & & & 1 \\
$\begin{array}{l}\text { Overweight } \\
\text { Obesity }\end{array}$ & $1.07(0.92-1.25)$ & $1.10(0.88-1.36)$ & $1.10(0.80-1.52)$ & $0.96(0.66-1.41)$ \\
& $1.35(1.10-1.66)$ & $1.31(0.98-1.74)$ & $1.62(1.10-2.36)$ & $1.20(0.74-1.94)$ \\
13-14 years old & & & & 1 \\
Normal weight & 1 & 1 & 1 & $1.01(0.68-1.51)$ \\
Overweight & $1.03(0.84-1.28)$ & $0.88(0.66-1.16)$ & $1.09(0.88-1.36)$ & $0.86(0.31-2.41)$ \\
Obesity & $0.62(0.34-1.13)$ & $0.52(0.22-1.21)$ & $1.04(0.60-1.79)$ & \\
\hline
\end{tabular}

OR: Odds Ratio. CI: Confidence interval. Adjusted by gender, cat and dog keeping, maternal education, parental asthma and parental smoking.

No significant influence of obesity on asthma prevalence was observed in the adolescent group.

\section{Discussion}

The results of this study suggest that obesity is associated with a higher asthma prevalence in 6-7 year old children, but not in the 13-14 year-old adolescents.

The results of previous studies are inconsistent, given that some studies did not find a relationship between obesity and asthma, ${ }^{5,6,14}$ while others observed an increase in the prevalence of asthma in obese children. ${ }^{3,4,15}$

Some studies even suggest the possibility of reverse causality, in that the asthma would be the cause of the obesity. ${ }^{16,17}$

Several mechanisms have been established that could justify the increase in prevalence in obesity.

Obesity is associated with various comorbidities that could increase asthma symptoms such as gastroesophageal reflux disease (GERD) or obstructive sleep apnoea syndrome (OSAS). ${ }^{18,19}$

On the other hand, some regions of the human genome, such as chromosomes 5,6,11 and 12 are associated with both asthma and obesity. ${ }^{20}$

Some authors suggest that obesity restricts mechanical conditions of the respiratory system, reducing chest wall compliance, increasing respiratory effort, or altering lung elastic retraction. ${ }^{21,22}$

Obesity also increases the prevalence of atopy, due to changes in cytokines, modification of lymphocyte activity, and favouring Th2 differentiation. ${ }^{20,23}$ 
Another mechanism could be the increase in systemic inflammation, since adipose tissue can produce cytokines such as, TNF-alpha, IL-6 or eotaxin. ${ }^{19,24,25}$ An increase has also been observed in inflammation markers, such as CRP or fibrinogen in obese asthmatics, compared to non-obese asthmatics. $^{26}$

Some hormonal mechanisms seem to take part in these processes, since high levels of leptin and a low adiponectin have been associated with a higher asthma prevalence. ${ }^{27,28,29}$ Leptin is involved in breathing control, as well as in systemic inflammatory processes, whilst adiponectin would produce the opposite effect. ${ }^{19,24,27,28}$

It has also been observed that obese asthmatics have a lower response to glucocorticoids, measured by a lower expression of protein-kinases. ${ }^{30-32}$

The difference in the effect of obesity that we observed between the 6-7 year-old group (where the asthma prevalence is increased), and the adolescents, in whom no significant effect could be associated, at least in part, with the low prevalence of obesity in this population. This obesity prevalence, which was $2.2 \%$, places us in the lowest values in the European population. Meanwhile, $9.6 \%$ of the 6-7 year-olds are obese. ${ }^{33}$

Another aspect to consider is the methodology of the ISAAC study, as the parents answered the questionnaire in the 6-7 year age group, while the adolescents gave their own responses. It is known that this may lead to some differences in the perception of the symptoms. ${ }^{11,34}$

The inconsistencies in the literature could be partly related to methodological differences between the different studies. On the other hand, it includes different population ages. Thus, in the study by Brenner, a group of 12-18 year-olds ${ }^{14}$ were analysed, two studies included a 4-11 yearold population, ${ }^{6}$ van Gysel between 3.4 and 14.8 years, ${ }^{35}$ and Chu 16-16 year-olds. ${ }^{4}$

The definition of obesity is also different, since some authors used a pre-defined cut-off point as in our case ${ }^{15,35}$ and others a percentile of the distribution of their population. ${ }^{3,4,6,14}$

\section{Limitations and strengths}

The main strengths of our study are based on the use of a validated methodology, with a large sample size, and the random selection of the subjects included.

As limitations, it should be noted that on being a cross- sectional study it could only identify the relationships but not determine the causality. On the other hand, the data obtained came from a questionnaire, with no objective measurements of the disease or the risk factors.

\section{Conclusion}

In conclusion, the results of our study reinforce the hypothesis that obesity is associated with the increase in prevalence of asthma symptoms in the child population, although this relationship disappears in adolescents.

\section{Ethical disclosures}

Patients' data protection. Confidentiality of data. The authors declare that they have followed the protocols of their work centre on the publication of patient data and that all the patients included in the study have received sufficient information and have given their informed consent in writing to participate in that study. 
Right to privacy and informed consent. Right to privacy and informed consent. The authors have obtained the informed consent of the patients and/or subjects mentioned in the article. The author for correspondence is in possession of this document.

Protection of human subjects and animals in research. Protection of human and animal subjects. The authors declare that no experiments were performed on humans or animals for this investigation.

\section{Conflict of interest}

The authors have not any conflict of interest.

\section{Acknowledgment}

This work was funded by Maria Jose Jove Foundation

\section{References}

1. Asher MI, Montefort S, Björkstén B, Lai CK, Strachan DP, Wei- land SK, et al. Worldwide time trends in the prevalence of symptoms of asthma, allergic rhinoconjunctivitis, and eczema in childhood: ISAAC phases one and three repeat multicountry cross-sectional surveys. Lancet. 2006;368:733-43.

2. Han JC, Lawlor DA, Kimm SY. Childhood obesity. Lancet. 2010;375:1737-48.

3. Cibella F, Cuttitta G, La Grutta S, Melis MR, Bucchieri S, Viegi G. A cross-sectional study assessing the relationship between BMI, asthma, atopy, and eNO among schoolchildren. Ann Allergy Asthma Immunol. 2011;107:330-6.

4. Chu YT, Chen WY, Wang TN, Tseng HI, Wu JR, Ko YC. Extreme BMI predicts higher asthma prevalence and is associated with lung function impairment in school-aged children. Pediatr Pulmonol. 2009;44:472-9.

5. Eneli IU, Karmaus WK, Davis S, Kuehr J. Airway hyperre-sponsiveness and body mass index: the Child Health and Environment Cohort Study in Hesse. Germany Pediatr Pulmonol. 2006;41:530-7.

6. To T, Vydykhan TN, Dell S, Tassoudji M, Harris JK. Is obesity associated with asthma in young children? J Pediatr. 2004;144:162-8

7. Zhang G, Khoo SK, Laatikainen T, Pekkarinen P, Vartiainen E, von Hertzen L, et al. Opposite gene by environment interactions in Karelia for CD14 and CC16 single nucleotide polymorphisms and allergy. Allergy. 2009;64:1333-41.

8. von Mutius E, Martinez FD, Fritzsch C, Nicolai T, Roell G, Thie- mann HH. Prevalence of asthma and atopy in two areas of West and East Germany. Am J Respir Crit Care Med. 1994;149: 358-64.

9. Garcia-Marcos L, Canflanca IM, Garrido JB, Varela AL, Garcia- Hernandez G, Guillen Grima F, et al. Relationship of asthma and rhinoconjunctivitis with obesity, exercise and Mediter- ranean diet in Spanish schoolchildren. Thorax. 2007;62: 503-8.

10. López-Silvarrey Varela A, González Barcala FJ, Paz Esquete JJ, Pérez Castro TR, Valdés Cuadrado L, Castro Iglesias A. Prevalence of asthma and rhinitis symptoms in A Coruña (Spain). An Pediatr (Barc). 2007;66:146-53.

11. The International Study of Asthma and Allergies in Childhood (ISAAC) Steering Committee. Worldwide variations in the preva- lence of asthma symptoms: the International Study of Asthma and Allergies in Childhood (ISAAC). Eur Respir J 1998;12: 315-35.

12. Yarnell JW, Stevenson MR, MacMahon J, Shields M, McCrum EE, Patterson CC, et al Smoking, atopy and certain furry pets are major determinants of respiratory symptoms in children: the International Study of Asthma and Allergies in Childhood Study (Ireland). Clin Exp Allergy. 2003;33: 96-100.

13. Cole TJ, Bellizzi MC, Flegal KM, Dietz WH. Establishing a standard definition for child overweight and obesity worldwide: international survey. BMJ. 2000;320:1240-3. 
14. Brenner JS, Kelly CS, Wenger AD, Brich SM, Morrow AL. Asthma and obesity in adolescents: is there an association? J Asthma. 2001;38:509-15.

15. Wang HY, Pizzichini MM, Becker AB, Duncan JM, Ferguson AC, Greene JM, et al. Disparate geographic prevalences of asthma, allergic rhinoconjunctivitis and atopic eczema among adolescents in five Canadian cities. Pediatr Allergy Immunol. 2010;21:867-77.

16. Hasler G, Gergen PJ, Ajdacic V, Gamma A, Eich D, Rössler W, et al. Asthma and body weight change: a 20 -year prospec- tive community study of young adults. Int J Obes (Lond). 2006;30:1111-8.

17. Vahlkvist S, Pedersen S. Fitness, daily activity and body compo- sition in children with newly diagnosed, untreated asthma. Allergy. 2009;64:1649-55.

18. Pakhale S, Doucette S, Vandemheen K, Boulet LP, McIvor RA, Fitzgerald JM, et al. A comparison of obese and nonobese people with asthma: exploring an asthma-obesity interaction. Chest. 2010;137:1316-23.

19. Rabec C, de Lucas Ramos P, Veale D. Respiratory complications of obesity. Arch Bronconeumol. 2011;47:252-61.

20. Delgado J, Barranco P, Quirce S. Obesity and asthma. J Investig Allergol Clin Immunol. 2008;18:420-5.

21. Gonzalez-Barcala FJ, Takkouche B, Valdes L, Leis R, Alvarez- Calderon P, Cabanas R, et al. Body composition and respiratory function in healthy non-obese children. Pediatr Int. 2007;49:553-7.

22. Lazarus R, Gore CJ, Booth M, Owen N. Effects of body composition and fat distribution on ventilatory function in adults. Am J Clin Nutr. 1998;68:35-41.

23. Hersoug LG, Linneberg A. The link between the epidemics of obesity and allergic diseases: does obesity induce decreased immune tolerance? Allergy. 2007;62:1205-13.

24. Sin DD, Sutherland ER. Obesity and the lung: 4. Obesity and asthma. Thorax. 2008;63:1018-23.

25. Vasudevan AR, Wu H, Xydakis AM, Jones PH, Smith EO, Sweeney JF, et al. Eotaxin and obesity. J Clin Endocrinol Metab. 2006;91:256-61.

26. Lessard A, Turcotte H, Cormier Y, Boulet LP. Obesity and asthma: a specific phenotype? Chest. 2008;134:317-23.

27. Giouleka P, Papatheodorou G, Lyberopoulos P, Karakatsani A, Alchanatis M, Roussos $\mathrm{C}$, et al. Body mass index is associated with leukotriene inflammation in asthmatics. Eur J Clin Invest. 2011;41:30-8.

28. Kattan M, Kumar R, Bloomberg GR, Mitchell HE, Calatroni A, Gergen PJ, et al. Asthma control, adiposity, and adipokines among inner-city adolescents. J Allergy Clin Immunol. 2010;125:584-92.

29. Nagel G, Koenig W, Rapp K, Wabitsch M, Zoellner I, Weiland SK. Associations of adipokines with asthma, rhinoconjunctivitis, and eczema in German schoolchildren Pediatr Allergy Immunol. 2009;20:81-8.

30. Sutherland ER, Goleva E, Strand M, Beuther DA, Leung DY. Body mass and glucocorticoid response in asthma. Am J Respir Crit Care Med. 2008;178:682-7.

31. Sutherland ER, Lehman EB, Teodorescu M, Wechsler ME, National Heart Lung, and Blood Institute's Asthma Clinical Research Network. Body mass index and phenotype in subjects with mild-to-moderate persistent asthma. J Allergy Clin Immunol. 2009;123:1328-34.

32. Boulet LP, Franssen E. Influence of obesity on response to fluti- casone with or without salmeterol in moderate asthma. Respir Med. 2007;101:2240-7.

33. Lissau I, Overpeck MD, Ruan WJ, Due P, Holstein BE, Hediger ML. Body mass index and overweight in adolescents in 13 European countries, Israel, and the United States. Arch Pediatr Adolesc Med. 2004;158:27-33.

34. Decker K, Meyer K, Littlefield D, Thompson WD. Similar asthma prevalence estimates obtained from preadolescent and parent survey responses. J Clin Epidemiol. 2008;61:611-6.

35. Van Gysel D, Govaere E, Verhamme K, Doli E, De Baets F. Body mass index in Belgian schoolchildren and its relationship with sensitization and allergic symptoms. Pediatr Allergy Immunol. 2009;20:246-53 